\title{
Research on the influence of driving harmonic on electromagnetic field and temperature field of permanent magnet synchronous motor
}

\author{
Hongbo QiU ${ }^{1}$, Wenfei Yu ${ }^{1}$, Yonghui LI $^{2}$, CUNXIANG YANG ${ }^{1}$ \\ ${ }^{1}$ College of electric and information engineering \\ Zhengzhou University of Light Industry \\ Zhengzhou 450002, China \\ e-mail: \{qiuhongbohrb/bijiaohao22/yangcx77777\}@163.com \\ ${ }^{2}$ Luoyang Railway Information Engineering School \\ Luoyang 471000, China \\ e-mail:kidlook@163.com
}

(Received: 29.06.2016, revised: 15.12.2016)

\begin{abstract}
At present, the drivers with different control methods are used in most of permanent magnet synchronous motors (PMSM). A current outputted by a driver contains a large number of harmonics that will cause the PMSM torque ripple, winding heating and rotor temperature rise too large and so on. In this paper, in order to determine the influence of the current harmonics on the motor performance, different harmonic currents were injected into the motor armature. Firstly, in order to study the influence of the current harmonic on the motor magnetic field, a novel decoupling method of the motor magnetic field was proposed. On this basis, the difference of harmonic content in an air gap magnetic field was studied, and the influence of a harmonic current on the air gap flux density was obtained. Secondly, by comparing the fluctuation of the motor torque in the fundamental and different harmonic currents, the influence of harmonic on a motor torque ripple was determined. Then, the influence of different current harmonics on the eddy current loss of the motor was compared and analyzed, and the influence of the drive harmonic on the eddy current loss was obtained. Finally, by using a finite element method (FEM), the motor temperature distribution with different harmonics was obtained.

Key words: air gap flux density, eddy current loss, harmonic, magnetic field decoupling, torque ripple
\end{abstract}

\section{Introduction}

At present, because PMSM with variable frequency speed regulation has the advantages of superior starting performance and excellent speed regulation performance, it has been widely used in industrial production and daily life. However, the drive controller power supply con- 
tains a lot of time harmonic that will affect the air gap flux density, torque ripple, eddy current loss and so on [1-3]. On one hand, the motor running high-frequency electromagnetic noise is loud [4], and the motor efficiency is reduced. On the other hand, due to the motor rotor has difficult heat dissipation, eddy current loss produced by permanent magnet will cause permanent magnet (PM) temperature rise too high [5-7], even partial irreversible demagnetization, which will seriously influence motor performance and operation reliability [8-9]. So it is significant to study the effect of harmonics on the motor performance.

In recent years, there are many experts and scholars who study the power supply of the driver, and some results have been obtained. Reference [1] proposed an analytical model that can evaluate the influence factors of current harmonics. Reference [6] represented the magnet eddy-current loss was mainly produced by the carrier harmonics of the PWM inverter and that the axial length of the divided magnet should be smaller than the skin depth of the eddy currents produced by the major harmonics for the loss reduction. Reference [10] proposed harmonic current suppression control of a PM motor in $\alpha \beta$ coordinates by using repetitive perfect tracking control with the PWM-hold model. Reference [11] studied the relationship between converter parameters and harmonic iron loss, and the formula of the iron loss in the power supply of the inverter was modified. Reference [12] proposed a current filtering strategy which weakened the 5th and the 7th harmonic currents in the stator. Reference [13] proposed a novel design for the elimination of radial air-gap flux density harmonics of permanent magnet motors. Reference [14] proposed and studied the phase-shifted chaotic space vector modulation scheme for harmonic performance improvement in paralleled voltage-source inverters fed permanent magnet synchronous motor drive. Reference [9] focused on the analysis and development of low-current harmonics and presented a zero-axis current estimator auxiliary vector control method to compensate for three multiples of the voltage harmonic. From references $[9,15$ and 16], it is seen that, by injecting harmonic currents, resistive losses in the stator can be minimized along with the reduction of torque ripple. The harmonic current in the stator winding is the research object of this paper. The influence of the harmonic current on the performance of PMSM is analyzed, and the influence of the harmonic on air gap flux density, torque ripple, eddy current loss and temperature of PM is determined.

In the present study, firstly, a two dimensional FEM is established. A novel method of decoupling the motor magnetic field is presented. The difference of harmonic content in the air gap magnetic field of the fundamental wave and different order harmonics is studied. By analyzing, the influence of the harmonic current on the air gap flux density is obtained. Secondly, by comparing the motor torque fluctuation wave of the fundamental current with the harmonic current of a different order, amplitude and phase angles, the influence of a harmonic of a different order, amplitude and phase angles on motor torque fluctuation is determined. Then, the influence of the different current harmonics on the eddy current loss of the motor rotor is compared and analyzed, and the influence of the drive harmonic of a different order, amplitude and phase angles on the eddy current loss is obtained. Finally, based on the FEM, the motor temperature distribution under different harmonic conditions is obtained. In this paper, the research results lay the foundation for the study of the loss and vibration of the drive motor, and provide a way to improve the motor performance. 


\section{Prototype parameters and harmonic analysis}

\subsection{Prototype parameters}

In this paper, taking a $10 \mathrm{~kW}, 2000 \mathrm{r} / \mathrm{min}$ PMSM as an example, the effect analysis of a harmonic on the performance of the PMSM is made. The two dimensional (2D) FEM of the prototype is shown in Fig. 1, and the basic parameters of PMSM are shown in Table 1.

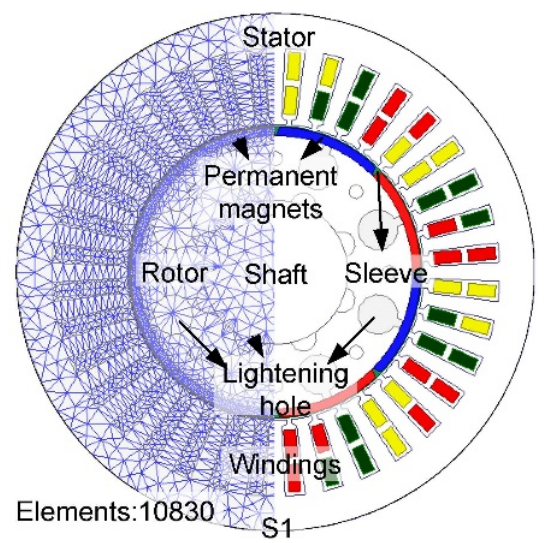

Fig. 1. FEM model of the prototype

In order to facilitate the influence study of a harmonic on the motor, the following assumptions are made:

(a) A displacement current and skin effect in the stator windings are ignored.

(b) Materials are isotropic. Permeability and conductivity of the materials are constant except the stator core and the rotor yoke.

(c) The material permeability and conductivity are constant ignoring the influence of temperature.

Based on the above assumptions, the 2D cross section of the motor perpendicular to axial direction is selected as the analysis model shown in Fig. 1, and the vector magnetic potential $A$ only has $z$-component. Considering the saturation, the transient 2D electromagnetic field calculation equation would be (1), in which the permanent magnet is simulated by a current density source [17].

$$
\left\{\begin{array}{l}
\Omega:\left\{\frac{\partial}{\partial x}\left(\frac{1}{\mu} \frac{\partial A_{z}}{\partial x}\right)+\frac{\partial}{\partial y}\left(\frac{1}{\mu} \frac{\partial A_{z}}{\partial y}\right)=-\left(J_{z}-\sigma \frac{\mathrm{d} A_{z}}{\mathrm{~d} t}\right),\right. \\
S_{1}: A_{z}=0 \\
P M: \frac{1}{\mu_{1}} \frac{\partial A_{z}}{\partial n}-\frac{1}{\mu_{2}} \frac{\partial A_{z}}{\partial n}=J_{s},
\end{array}\right.
$$

where: $\Omega$ is the calculation region, $A_{z}$ and $J_{z}$ represent the magnetic vector potential and the source current density in the $z$-axial component respectively, $J_{S}$ is the equivalent current density of permanent magnets, $n$ is the normal direction of a permanent magnet boundary, $\sigma$ is 
the conductivity, $\mu$ is the permeability, $S_{1}$ is the Dirichlet boundary conditions, $\mu_{1}$ and $\mu_{2}$ represent the relative permeability, $t$ is the time.

Table 1. Parameters of the model

\begin{tabular}{l|c|c}
\hline \multicolumn{1}{c|}{ Parameters } & Value & Unit \\
\hline Rated power & 10 & $\mathrm{~kW}$ \\
\hline Rated speed & 2000 & $\mathrm{r} / \mathrm{min}$ \\
\hline Pole number & 8 & \\
\hline Axial length & 102 & $\mathrm{~mm}$ \\
\hline Rotor magnetic circuit structure & surface-mounted type & \\
\hline Stator outer diameter & 180 & $\mathrm{~mm}$ \\
\hline Stator inner diameter & 103 & $\mathrm{~mm}$ \\
\hline Slot number & 36 & \\
\hline Number of parallel branches & 1 & \\
\hline Winding connection type & $\mathrm{Y}$ & \\
\hline
\end{tabular}

\subsection{The establishment of harmonic and research method}

In order to prevent the PMSM demagnetization caused by armature reaction and to optimize the motor performance, in this paper, the vector control mode $i_{d}=0$ is chosen in PMSM based on the principle of permanent magnet motor control technology.

The synthetic electromotive force in the stator armature winding not only contains the fundamental wave but also contains each harmonic. The current in windings is obviously not sinusoidal. The fundamental wave rotating magnetic field is generated by a fundamental wave current, and the magnetic field is generated by rotor permanent magnets. The main electromagnetic torque is formed by the fundamental wave rotating magnetic field and the magnetic field. The rotation speed and rotation direction of the synthetic rotating magnetomotive force generated by the harmonics are different from those of the rotor's. The speed of the synthetic rotating magnetomotive force is relatively higher than the rotor speed. The eddy current loss and magnetic hysteresis loss in the rotor are generated by the synthetic rotating magnetomotive force, which causes a phenomenon in which the rotor temperature rise is higher than that of the stator. At the same time, the motor efficiency decreases, and the motor vibration and noise increase $[1,6]$.

The harmonics affecting the motor are mainly the 5th, 7th, 11th, 13th harmonics. The 5 th 7th 11th 13th harmonics are chosen in this paper, for each harmonic, five amplitudes are set, they are $2 \%, 4 \%, 6 \%, 8 \%$ and $10 \%$ of the fundamental current amplitude respectively. The artificial injection harmonic method was adopted and different orders of harmonic currents and a fundamental current are injected. The superposition of different times of the harmonic currents and fundamental current were taken as the excitation source of the motor, the influence of a different order, amplitude and the phase angle of the harmonic current on the motor performance in the excitation power supply is studied. The input current can be expressed as Eq. (2): 


$$
\left\{\begin{array}{l}
I_{A} \sin (2 \pi f t)+k I_{A} \sin \left(2 v \pi f t+\varphi_{0}\right), \\
I_{B} \sin (2 \pi f t-2 \pi / 3)+k I_{B} \sin \left(2 v \pi f t-2 v \pi / 3+\varphi_{0}\right), \\
I_{C} \sin (2 \pi f t-2 \pi / 3)+k I_{C} \sin \left(2 v \pi f t+2 v \pi / 3+\varphi_{0}\right),
\end{array}\right.
$$

where: $I_{A}, I_{B}, I_{C}$ are the peak values of the current $A$, current $B$, current $C$ respectively. $k$ is the ratio of the harmonic amplitude of the fundamental amplitude. $v$ is the harmonic order. $\varphi_{0}$ is the harmonic initial phase.

\section{The influence of harmonic current on air gap magnetic field}

\subsection{Analysis of air gap magnetic field}

During the motor normal operation, because of the non-sine stator armature current waveform and stator slot, the wave of the magnetomotive force is non-sine, which causes a lot of space and time harmonic magnetic fields in the air gap magnetic field. The time harmonic magnetic field is the spatial fundamental magnetic field generated by the harmonic exciting current, and the motor air gap main magnetic field consists of the time harmonic magnetic field and the fundamental magnetic field. The direction of the $K$-th $(K=6 n-1, n=1,2,3 \ldots)$ time harmonic magnetic field is reversed to the direction of the fundamental magnetic field and the speed is $K$ times of the fundamental magnetic field. The direction of the $K$-th $(K=6 n+1, n=1,2,3 \ldots)$ time harmonic magnetic field is the same as the direction of the fundamental magnetic field and the speed is also $K$ times of the fundamental magnetic field. Therefore, the eddy current is generated in rotor permanent magnets and in a sleeve. Finally, the eddy current loss increases $[1,4]$.

\subsection{Air gap magnetic field decoupling method}

According to the electrical machine theory, during the motor operation, the air gap magnetomotive force includes the stator current harmonic magnetomotive force and the equivalent magnetomotive force of the rotor permanent magnets [18]. The space harmonic magnetic field is produced by permanent magnets, and it rotates synchronously with the rotor. The eddy current cannot be induced by these harmonics, and eddy current loss cannot be produce. Therefore, the harmonics produced by the stator armature winding just induce the eddy current in the rotor.

The harmonic current generates a large amount of the eddy current loss in the rotor. The time and space harmonics are the main reasons which cause the eddy current loss [19]. The motor air gap magnetic field is composed of the magnetic field generated by a stator current and that is generated by permanent magnets. A motor magnetic field decoupling method was proposed, which separated the magnetic field generated by the stator current from the motor air gap magnetic field. The influence of the high harmonic content of the stator armature current on the motor air gap magnetic field is analyzed, and the influence of the stator armature current on the air gap flux density is obtained. 
An air gap magnetic field decoupling method and procedure are as follows:

(1) Three phase stator armature currents are extracted when the motor operates under the rated condition.

(2) The three-phase stator armature currents are decomposed by FFT and the amplitude and phase of each harmonic wave are determined.

(3) The mixed current of the fundamental current and the ideal harmonic is used as the excitation to the stator armature.

(4) The permanent magnets are demagnetized completely and driven motor rotation at the rated speed.

Fig. 2 shows the air gap flux density waveforms under different motor operating conditions. Curve1 is the air gap flux density waveform at no-load operation, curve2 is the air gap flux density waveform at rated load operation, and curve3 is the air gap flux density waveforms generated by the stator current after the air gap magnetic field decoupling. Actually, due to the influence of armature reaction, the armature field should act in the $q$-axis, and the synthetic magnetic field under load operation lags behind the magnetic field under no-load operation $20 \mathrm{deg}$. In order to facilitate the contrast analysis, the phase difference of the synthetic magnetic field is artificially adjusted to the same phase.

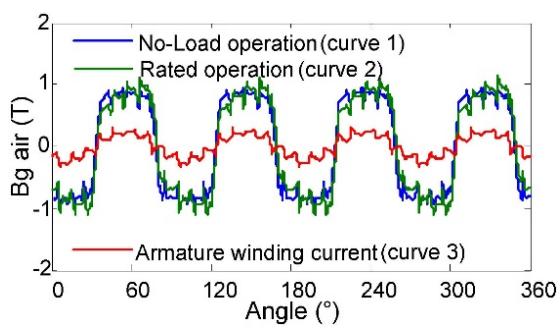

Fig. 2. The motor air gap flux density waveform under different operation conditions

When the harmonic order changes only, the influence of harmonic order variation on the motor electromagnetic field is studied. The fundamental current and the 5th, 7th, 11th, 13th harmonics whose amplitude is $10 \%$ of the fundamental current are injected through the method of artificial injection. The influence of the stator armature currents on the harmonic content of the air gap magnetic field in the motor is studied after the air gap magnetic field decoupling. The air gap magnetic field is only generated by the stator armature current. By using the FFT method, the air gap magnetic field of the fundamental current and each harmonic is decomposed respectively, and the harmonic content of the air gap magnetic field is shown in Fig. 3.

The content of the 5th, 7th, 11th and 13th harmonics in the air gap magnetic field is higher than that of others obviously. It can be concluded that the eddy current loss of the motor rotor is mainly caused by the 5 th, 7 th, 11 th, and 13 th harmonic currents.

Taking the air gap flux density harmonic content in the fundamental current as a reference value, when the 5th and 11th harmonic currents are input into the stator armature windings, the magnetic field content of the motor air gap fundamental wave decreases; when the 7th and 13th harmonic currents are input into the stator armature windings, the motor air gap funda- 
mental wave magnetic field content increases. The maximum air gap magnetic density value caused by the 5th and 11th harmonic becomes smaller, the average value increases. The air gap flux density maximum value caused by the 7 th and 13th harmonic becomes large, and the average value decreases.

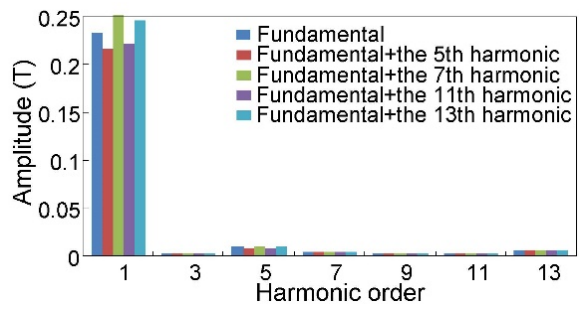

\section{The influence of harmonic current on torque}

A torque ripple factor and the average torque are two important parameters which could determine the stability of a permanent magnet motor. On the basis of the fundamental current, the different order harmonics with different amplitudes and phases were injected into the motor armature windings by the method of artificial injection and the influence of the harmonic current of different orders and amplitudes on the motor torque ripple and the average torque is analyzed.

\subsection{Effect of harmonic current amplitude on torque}

Due to the fact that the input voltage and current contain a lot of harmonic components, the harmonics of different order affects the motor torque ripple to a different degree. For the three-phase PMSM, when Y-type connection is adopted in the stator windings, the $3 K$-th $(K=1,2,3 \ldots)$ harmonics of the motor phase current are eliminated, so the influence of the $3 K$-th $(K=1,2,3 \ldots)$ harmonics on the motor performance is not considered and only the effect of the 5th, 7th, 11th and 13th harmonics on the motor performance are considered [20].

In the research of the PMSM torque ripple, the torque ripple coefficient is usually used to measure the motor stability. Eq. (3) is the torque ripple formula.

$$
\delta=\frac{\sqrt{\sum_{i=1}^{n}\left(T_{i \max }-T_{i \mathrm{av}}\right)^{2}}+\sum_{i=1}^{n}\left(T_{i \mathrm{av}}-T_{i \min }\right)^{2}}{\sum_{i=1}^{n} T_{i \mathrm{av}}}
$$

where: $\delta$ is the torque ripple coefficient. $T_{i \max }$ and $T_{i \min }$ are the maximum and minimum values of the torque ripple in the $i$-th cycle. $T_{i}$ av is the torque average value in the $i$-th cycle, $n$ is the number of computation cycles.

Under the motor rated operating condition, the fluctuation curve of the motor output torque is shown in Fig. 4a. The periodic fluctuations of the torque ripple curve appeared. The opera- 
tion cycle of the motor is $7.5 \mathrm{~ms}$. The average torque of the motor is $47.6 \mathrm{~N} \cdot \mathrm{m}$. The maximum torque is $49.5 \mathrm{~N} \cdot \mathrm{m}$ and the minimum torque is $45.6 \mathrm{~N} \cdot \mathrm{m}$. The motor torque fluctuation range is $3.9 \mathrm{~N} \cdot \mathrm{m}$ and the torque ripple coefficient is $5.75 \%$.

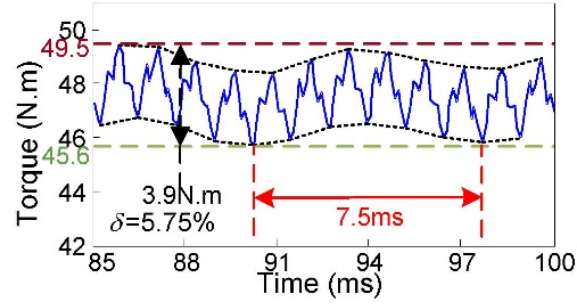

(a)

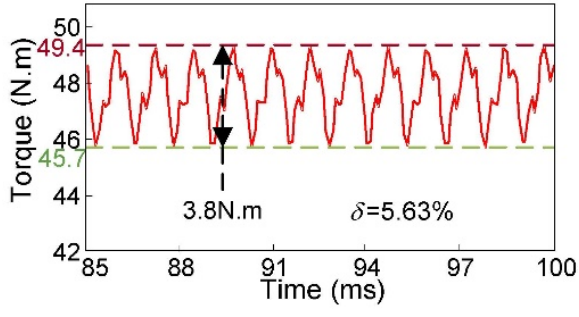

(b)

Fig. 4. The motor torque fluctuation curve under different situation: torque fluctuation curve at rated operation (a); torque fluctuation curve under fundamental current (b)

Firstly, in order to study the harmonic current influence on motor performance, a fundamental current of $133 \mathrm{~Hz}$ is injected into the armature windings, and the motor torque curve is shown in Fig. 4b. The data are regarded as the reference and are compared with other conditions when the harmonic current order is different.

When the fundamental current is injected into the stator armature windings, the average torque of the motor is $47.7 \mathrm{~N} \cdot \mathrm{m}$, the maximum torque is $49.4 \mathrm{~N} \cdot \mathrm{m}$ and the minimum torque is $45.7 \mathrm{~N} \cdot \mathrm{m}$. The motor torque fluctuation range is $3.7 \mathrm{~N} \cdot \mathrm{m}$ under stable conditions. The torque ripple coefficient is $5.63 \%$.

On the basis of the fundamental wave current, the influence of the 5th harmonic current with different amplitudes on the motor torque fluctuation curve is studied by the method of artificial injection. As soon as the harmonic amplitude changes, the influence of harmonic amplitude variation on the output torque is studied. The 5th harmonic amplitudes are $0 \%, 2 \%$, $4 \%, 6 \%, 8 \%$ and $10 \%$ of the fundamental current amplitude respectively. The motor torque fluctuation curve with different amplitude harmonic is shown in Fig. 5.

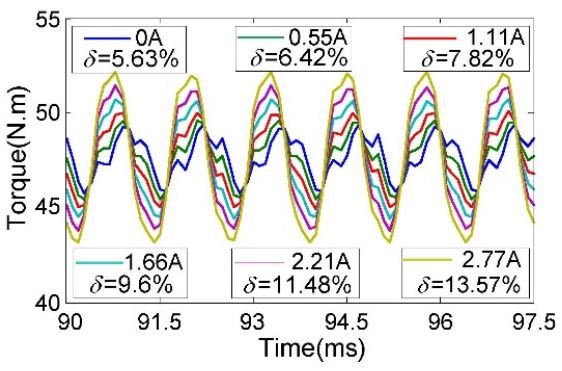

Fig. 5. The torque curve under fundamental wave and the 5th harmonic currents with different amplitudes

As is shown in Fig. 5, on the basis of the fundamental wave current, the larger the amplitude of the 5th harmonic current is, the larger the range of the motor torque fluctuation is, the higher the torque ripple coefficient of the motor is, the worse the stability of the motor is. 


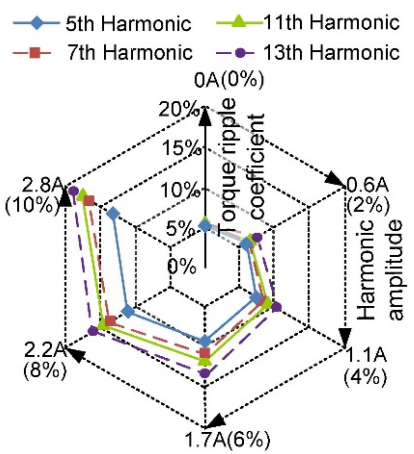

Fig. 6. The influence of the harmonic current with different amplitude on the motor torque ripple

The influences of a different order harmonics on the motor torque ripple are shown in Fig. 6. The fundamental current and different order harmonics current of different amplitudes are injected into the motor stator armature windings respectively.

On the basis of the fundamental wave current, the motor torque fluctuation range is $4.4 \mathrm{~N} \cdot \mathrm{m}, 5.8 \mathrm{~N} \cdot \mathrm{m}, 7.4 \mathrm{~N} \cdot \mathrm{m}, 9.3 \mathrm{~N} \cdot \mathrm{m}$ and $11.2 \mathrm{~N} \cdot \mathrm{m}$ when the 7 th harmonic current is loaded and the amplitudes are $2 \%, 4 \%, 6 \%, 8 \%, 10 \%$ of the fundamental wave. The torque ripple coefficient is $6.56 \%, 8.6 \%, 11.08 \%, 13.95 \%, 16.74 \%$ respectively. The fluctuation range of the motor torque increases with the increase of the harmonic amplitude.

After analyzing the influence of different order harmonic currents on the motor torque, the following conclusions could be concluded. The motor average torque is not affected by the harmonic currents of different amplitudes. However, with the increase of the harmonic current amplitude, the bigger the range of the motor torque fluctuation is and the higher the torque ripple coefficient of the motor is, the worse the stability of the motor is.

\subsection{The influence of harmonic current phase angle on torque}

Not only will the amplitude of the harmonic current affect the PMSM torque performance, but also the phase angle difference between the harmonic current and fundamental current will affect the motor average torque and torque ripple.

As soon as the harmonic initial phase changes, the influence of harmonic phase variation on the output torque is studied. When analyzing the influence of harmonic phase, the fundamental phase does not shift. As the current expression shows, the harmonic magnetic field generated by the harmonic current of the same order also shifts when the harmonic current initial phase is shifts from $0 \mathrm{deg}$ to $360 \mathrm{deg}$. The fundamental current and the 5 th harmonic current whose amplitude is $10 \%$ of the fundamental current are injected into the motor armature windings. The harmonic initial phase angle changes from 0 deg to $360 \mathrm{deg}$. The step length is $15 \mathrm{deg}$. Finally, the average torque and torque ripple coefficient with the change of a harmonic current phase are obtained as shown in Fig. 7.

From Fig. 7, it could be found that when the initial phase $\varphi_{0}$ of the 5th harmonic current increases from $15 \mathrm{deg}$ to $75 \mathrm{deg}$ gradually, the motor torque pulsating coefficient increases from $15.35 \%$ to $18.72 \%$ gradually. When the initial phase $\varphi_{0}$ increases from 75 deg to $165 \mathrm{deg}$, the motor pulsating coefficient has a downward trend from $18.72 \%$ to $11.95 \%$. When 
the initial phase $\varphi_{0}$ increases from $210 \mathrm{deg}$ to $255 \mathrm{deg}$, the torque ripple coefficient decreases. When the initial phase $\varphi_{0}$ increases from $255 \mathrm{deg}$ to $345 \mathrm{deg}$, the motor torque ripple coefficient increases from $8.79 \%$ to $15.77 \%$ gradually.

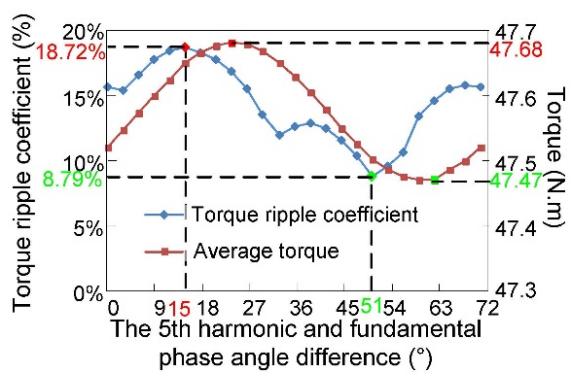

Fig. 7. The influence of the 5th harmonic current initial phase $\varphi_{0}$ on the motor torque ripple

When the 5th harmonic current initial phase $\varphi_{0}$ is $75 \mathrm{deg}$, the motor torque fluctuation range is maximum and the value is $12.6 \mathrm{~N} \cdot \mathrm{m}$, and the motor ripple coefficient is $18.72 \%$. When the initial phase $\varphi_{0}$ is $255 \mathrm{deg}$, the motor torque ripple range is minimum and the value is $5.9 \mathrm{~N} \cdot \mathrm{m}$. The torque pulsation coefficient is $8.79 \%$.

The average torque fluctuation curve changes according to sinusoidal law. The average torque reaches a maximum value of $47.68 \mathrm{~N} \cdot \mathrm{m}$ when the 5 th harmonic initial phase $\varphi_{0}$ is $120 \mathrm{deg}$. The average torque reaches a maximum value of $47.47 \mathrm{~N} \cdot \mathrm{m}$ when the 5 th harmonic current initial phase $\varphi_{0}$ is $300 \mathrm{deg}$.

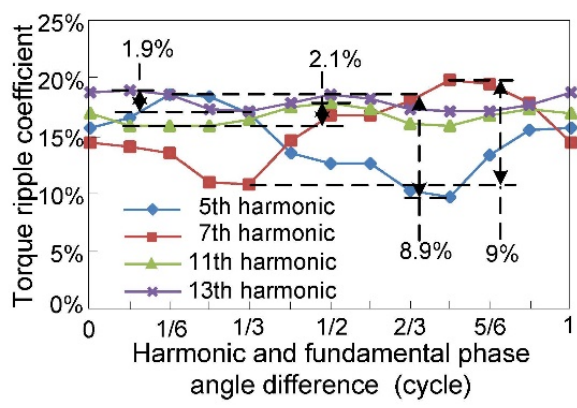

Fig. 8. The influence of harmonic initial phase $\varphi_{0}$ on torque pulsating

Not only does the armature current contain the 5th harmonic, but also contains the 7th, 11 th and 13th harmonics. The fundamental current and each harmonic current with $10 \%$ of the fundamental current amplitude are injected into the motor armature windings. Fig. 8 shows the torque pulsating changes of different harmonic currents of a different initial phase $\varphi_{0}$.

As shown in Fig. 8, when the 5th, 7th, 11th and 13th harmonic initial phase $\varphi_{0}$ change within $360 \mathrm{deg}$, the variation range of the motor torque pulsation coefficient is $8.9 \%, 9 \%$, $2.1 \%, 1.9 \%$ respectively. The change of the torque fluctuating range caused by the 5 th and 7 th harmonic currents is larger than that caused by the 11th and 13th harmonic currents with the change of the initial phase. 
The initial phase $\varphi_{0}$ change not only affects the motor torque pulsation, but also affects the motor average torque. Fig. 9 shows the variation of the motor average torque when each harmonic current initial phase $\varphi_{0}$ changes within $360 \mathrm{deg}$.

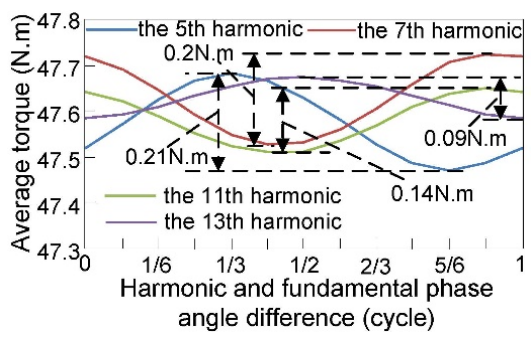

Fig. 9. The influence of harmonic initial phase $\varphi_{0}$ on average torque

With the change of the initial phase $\varphi_{0}$ of the 5th, 7th, 11 th and 13 th harmonic currents the fluctuation ranges of the motor average torque are $0.21 \mathrm{~N} \cdot \mathrm{m}, 0.2 \mathrm{~N} \cdot \mathrm{m}, 0.14 \mathrm{~N} \cdot \mathrm{m}, 0.09 \mathrm{~N} \cdot \mathrm{m}$ respectively. When the 5 th and 7 th harmonic currents flow, the motor average torque is larger than that when the 11th and 13th harmonic currents flow.

\section{Influence of harmonic current on eddy current loss and permanent magnet temperature}

\subsection{Effect of harmonic current amplitude on eddy current loss and temperature rise of permanent magnets}

A low order harmonic magnetic field not only generates an eddy current in the sleeve, but also generates a large eddy current in the rotor permanent magnets. When the motor operates under loaded condition, a lot of eddy currents will be generated on the sleeve surface, which will cause additional eddy current loss and hysteresis loss. The motor rotor iron loss increases with the increase of frequency, harmonic will cause the motor iron loss to increase rapidly.

In this paper, the eddy current loss of the rotor caused by a harmonic current is studied by the method of artificial injection harmonic current with different amplitude. As shown in Fig. 10a, the maximum value of motor eddy current density under the action of an ideal fundamental current is $1.61 \times 10^{6} \mathrm{~A} / \mathrm{m}^{2}$. The eddy current loss of the permanent magnets and the sleeve is $10.1 \mathrm{~W}$. When the fundamental current and the 13th harmonic current whose amplitude is $10 \%$ of the fundamental current are injected into the motor armature windings, due to the impact of the harmonic magnetomotive force, an eddy current was formed on the rotor surface. As shown in Fig. 10b the maximum value of the motor eddy current density is $3.24 \times 10^{6} \mathrm{~A} / \mathrm{m}^{2}$.

Based on the FEM, a 2D motor temperature field model is built. In order to simplify the analysis and calculation of the temperature field, the following assumptions are proposed [21]:

1) The motor is continuous along the axial direction, and the axial temperature gradient is zero. 
2) Material is isotropic; the influence of temperature on thermal conductivity is ignored.

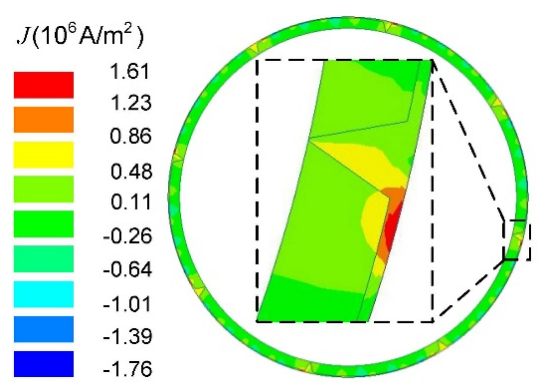

(a)

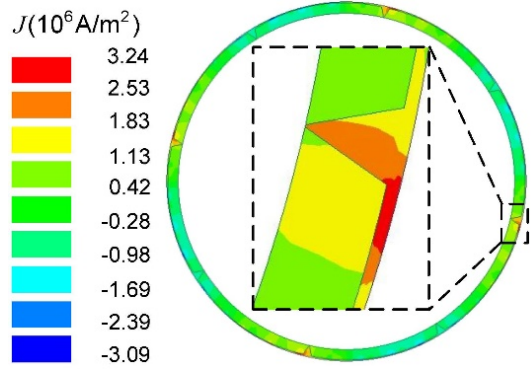

(b)

Fig. 10. The motor rotor eddy current density distribution: under the action of fundamental current (a); under the fundamental and the 13th harmonic current (b)

Based on the above assumptions, the 2D model could be established adopting the FEM. The heat transfer equation can be expressed as Eq. (4):

$$
\left.\begin{array}{l}
\frac{\partial}{\partial x}\left(\lambda_{x} \frac{\partial T}{\partial x}\right)+\frac{\partial}{\partial y}\left(\lambda_{y} \frac{\partial T}{\partial y}\right)=-q_{v} \\
\left.\lambda \frac{\partial T}{\partial x}\right|_{\Gamma}=\alpha\left(T-T_{f}\right)
\end{array}\right\},
$$

where: $T$ is the body temperature, $\lambda_{x}$ and $\lambda_{y}$ represent the thermal conductivity along the directions $x$ and $y, q_{v}$ is the heat generation density, the stator outer surface is the air natural convection heat dissipation, the third boundary condition is given as $\Gamma$ (the stator outer circle boundary), $\alpha$ is the heat transfer coefficient, $T_{f}$ is the temperature of the circumstance.

The ideal harmonic is injected by the method of artificial injection, the influence of harmonic frequency, amplitude and the phase angle on a motor temperature field is studied. Fig. 11a shows the motor temperature field distribution under the action of an ideal fundamental current. Fig. $11 \mathrm{~b}$ shows the motor temperature field distribution under the action of the fundamental current and the 13th harmonic current whose amplitude is $10 \%$ of the fundamental current.

As shown in Fig. 11, when the ideal fundamental wave current is injected into the motor winding, the motor winding temperature is $81.7^{\circ} \mathrm{C}$ and rotor permanent magnet temperature is $78.9^{\circ} \mathrm{C}$. When the fundamental current and the 13 th harmonic current whose amplitude is $10 \%$ of the fundamental current are injected into the motor armature windings, the motor winding temperature is $94^{\circ} \mathrm{C}$ and rotor permanent magnet temperature is $128.1^{\circ} \mathrm{C}$. Based on the above analysis method, the motor eddy current loss and the permanent magnet temperature distribution under different amplitudes of each harmonic are studied. As shown in Fig. 12, the change of the motor eddy current loss and the temperature increasing trend of the permanent magnet are studied under the fundamental current and the 5th ,7th, 11th and 13th harmonic current whose amplitude is $2 \%, 4 \%, 6 \%, 8 \%$ and $10 \%$ of the fundamental current respectively. 


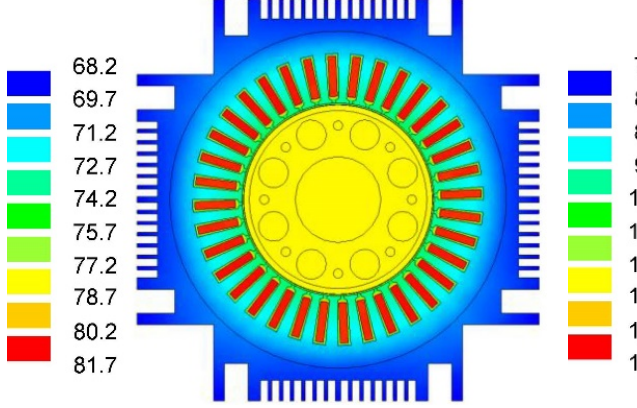

(a)

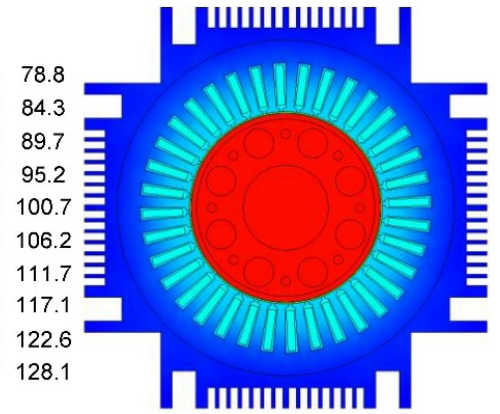

(b)

Fig. 11. The motor temperature distribution: under the action of fundamental current (a); under the fundamental and the 13th harmonic current (b)

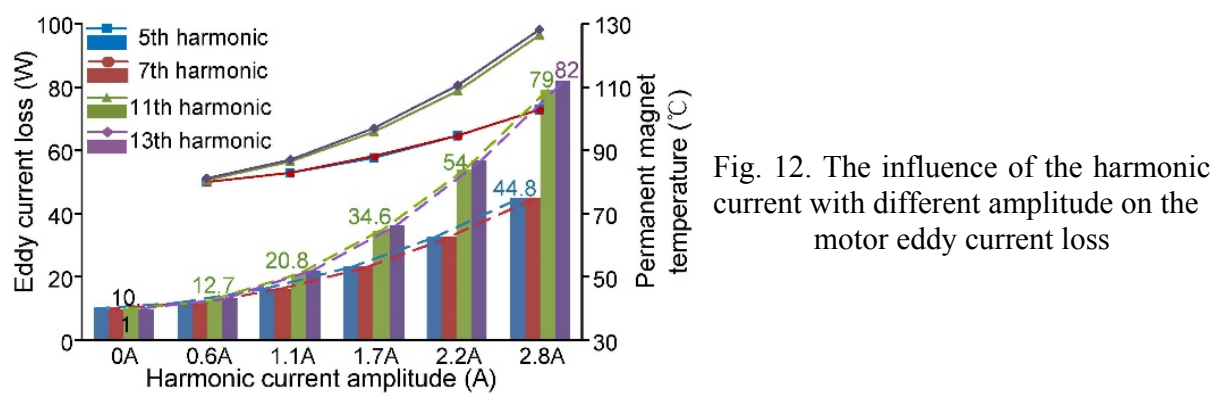

In general, the higher order harmonics causes the larger rotor eddy current loss and the higher temperature rise of permanent magnets when the amplitude of the harmonic current is constant. As shown in Fig. 12, when the amplitude of each harmonic current is $2.8 \mathrm{~A}$, the rotor eddy current loss generated by the 5 th harmonic current is $44.8 \mathrm{~W}$, the temperature of the rotor permanent magnets is increased by $23.7^{\circ} \mathrm{C}$, and the permanent magnet temperature is 1.3 times of the permanent magnet temperature when the fundamental current is injected. The rotor eddy current loss generated by the 13 th harmonic current is $82 \mathrm{~W}$.

In addition, with the increase of the harmonic amplitude, the eddy current loss of the rotor increases, and the temperature rise of the permanent magnets also increases. When the amplitude of the 11th harmonic current is $0.6 \mathrm{~A}, 1.1 \mathrm{~A}, 1.7 \mathrm{~A}, 2.2 \mathrm{~A}$ and $2.8 \mathrm{~A}$ respectively, the corresponding eddy current losses are $12.7 \mathrm{~W}, 20.8 \mathrm{~W}, 34.6 \mathrm{~W}, 54 \mathrm{~W}$ and $79 \mathrm{~W}$, the temperature rise of the rotor permanent magnets is $2.28 \%, 9.38 \%, 21.29 \%, 38.15 \%$ and $59.7 \%$ of the permanent magnet temperature when the fundamental current is injected.

However, the increase of the loss caused by the high order harmonic current is signifycantly higher than the increase of the loss caused by the lower harmonic current. When the amplitude of the harmonic current is $2.8 \mathrm{~A}$, the eddy current loss caused by the 5 th harmonic current increases by 3.44 times compared with that caused by the fundamental current, and the eddy current loss caused by the 13th current harmonic increases by 7.12 times compared with that caused by the fundamental current. 


\subsection{The influence of harmonic current phase angle on the eddy current loss and permanent magnets temperature}

The harmonic amplitude affects the motor eddy current loss, in addition, the harmonic initial phase is also one of the key factors affecting the motor eddy current loss. The 5th, 7th, 11 th and 13th harmonic currents whose amplitudes are $10 \%$ of the fundamental current are adopted. The rotor eddy current loss and the permanent magnet temperature rise are studied when harmonic initial phase $\varphi_{0}$ changes within 360 deg. The results are shown in Fig. 13.

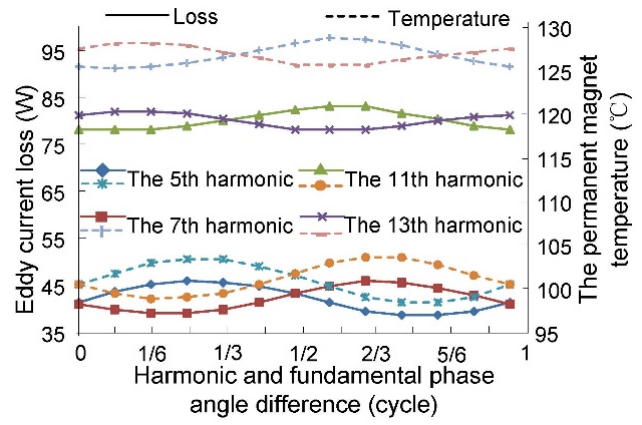

Fig. 13. The influence of harmonic initial phase on eddy current loss and permanent magnet temperature

As shown in Fig. 13, the variation regular of the eddy current loss generated by the 5th, 7th, 11th and 13th harmonic current is sinusoidal with the change of the phase angle. The motor eddy current loss generated by the 5 th harmonic current reaches a minimum value of $38.5 \mathrm{~W}$ when the 5 th harmonic initial phase $\varphi_{0}$ is $270 \mathrm{deg}$, and the temperature of the permanent magnets is $98.4^{\circ} \mathrm{C}$. The motor eddy current loss reaches a maximum value of $45.9 \mathrm{~W}$ when the 5th harmonic initial phase $\varphi_{0}$ is $90 \mathrm{deg}$, and the temperature of the permanent magnets is $103.4^{\circ} \mathrm{C}$. The eddy current loss is increased by $19.2 \%$, and the temperature rise of the permanent magnets is $5^{\circ} \mathrm{C}$, which is increased by $5.1 \%$.

The motor eddy current loss reaches a minimum value of $39 \mathrm{~W}$ when the 7 th harmonic initial phase $\varphi_{0}$ is $60 \mathrm{deg}$, and the temperature of the permanent magnets is $98.8^{\circ} \mathrm{C}$. The motor eddy current loss reaches a maximum value of $45.8 \mathrm{~W}$ when the 7 th harmonic initial phase $\varphi_{0}$ is $240 \mathrm{deg}$, and the temperature of the permanent magnets is $103.5^{\circ} \mathrm{C}$. The eddy current loss is increased by $17.4 \%$, and the temperature rise of the permanent magnets is $4.7^{\circ} \mathrm{C}$, which is increased by $4.8 \%$.

The motor eddy current loss reaches a minimum value of $78 \mathrm{~W}$ when the 11 th harmonic initial phase $\varphi_{0}$ is $30 \mathrm{deg}$, and the temperature of the permanent magnets is $125.3^{\circ} \mathrm{C}$. The motor eddy current loss reaches a maximum value of $83.2 \mathrm{~W}$ when the 11 th harmonic initial phase $\varphi_{0}$ is $210 \mathrm{deg}$, and the temperature of the permanent magnets is $128.7^{\circ} \mathrm{C}$. The eddy current loss is increased by $6.7 \%$, and the temperature rise of the permanent magnets is $3.4^{\circ} \mathrm{C}$, which is increased by $2.7 \%$.

The motor eddy current loss reaches a minimum value of $78.1 \mathrm{~W}$ when the 13 th harmonic initial phase $\varphi_{0}$ is $210 \mathrm{deg}$, and the temperature of the permanent magnets is $125.6^{\circ} \mathrm{C}$. The motor eddy current loss reaches a maximum value of $82 \mathrm{~W}$ when the 13 th harmonic initial phase $\varphi_{0}$ is $30 \mathrm{deg}$, and the temperature of the permanent magnets is $128.1{ }^{\circ} \mathrm{C}$. The eddy 
current loss is increased by $5 \%$, and the temperature rise of the permanent magnets is $2.5^{\circ} \mathrm{C}$, which is increased by $2 \%$.

\section{Experimental study}

In order to verify the correctness of the electromagnetic field and temperature field model, the experimental test of the prototype is carried out. The test system consists of a Magtrol dynamometer machine, YOKOGAWA power analyzer, industrial condensing unit, DSP data acquisition system, PMSM and other equipment. The experimental platform of the prototype is shown in Fig. 14. Test data and calculation data of the PMSM current are shown in Table 2 when the motor operates at different load conditions.

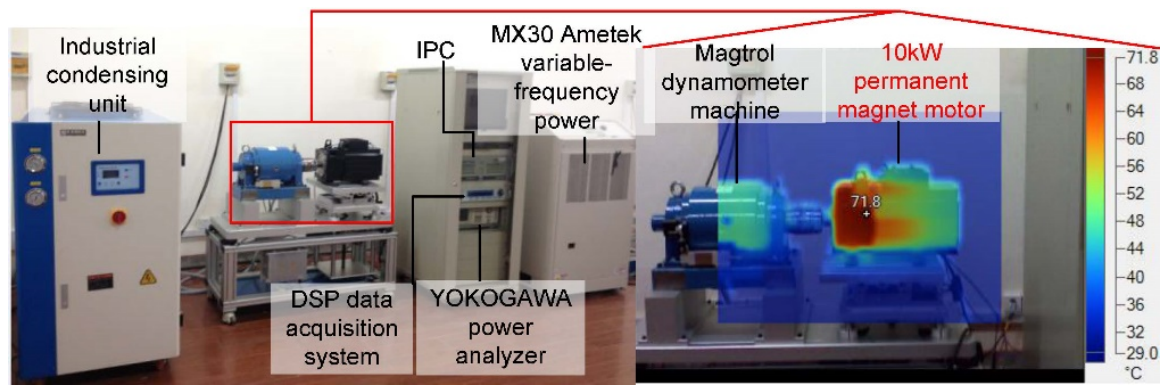

Fig. 14. Test platform of the prototype

In the experimental study, the temperature rise of the PMSM is tested at the rated load $(10 \mathrm{~kW})$ for a long time. The infrared thermal imager is adopted to obtain the temperature distribution of the motor outside surface as shown in Fig. 14.

Table 2. Test data and calculation results of PMSM at different conditions

\begin{tabular}{l|c|c|c}
\hline Torque & Experimental current & Simulation current & Change rate \\
\hline $25 \mathrm{~N} \cdot \mathrm{m}$ & $10.62 \mathrm{~A}$ & $10.23 \mathrm{~A}$ & $3.8 \%$ \\
\hline $36.4 \mathrm{~N} \cdot \mathrm{m}$ & $15.3 \mathrm{~A}$ & $15.4 \mathrm{~A}$ & $0.6 \%$ \\
\hline $47.7 \mathrm{~N} \cdot \mathrm{m}$ & $19.4 \mathrm{~A}$ & $19.8 \mathrm{~A}$ & $2 \%$ \\
\hline
\end{tabular}

Through the comparison of the above data analysis, it can be noticed that the experimental current values are basically consistent with the simulation current values when the permanent magnet motor operates under different loads, and the deviation is less than $5 \%$, which corresponds with the practical requirements of the project.

The motor cooling system is shown in Fig. 15. The motor uses fan and ventilating ducts to accelerate the heat dissipation. It can be seen that the motor surface temperature increases from the inlet to the outlet of the cooling medium (air). The heat amount transferred by the cooling medium decreases with the increase of the temperature. In addition, at the end of the 
ventilation system, the wind speed will be significantly reduced, so the hottest area is located at the end of the ventilation system.

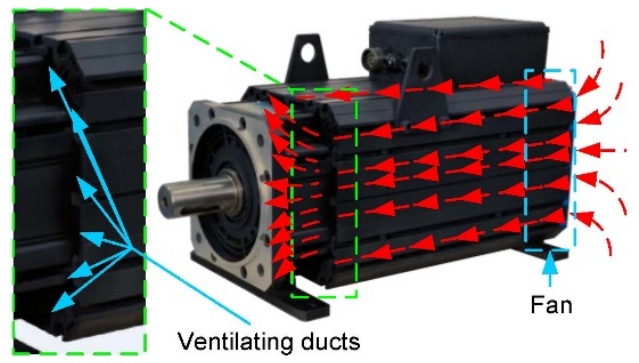

Fig. 15. The motor cooling system

Because the heat source in the motor interior larger and the heat dissipation structure is complex, only the surface temperature of the motor casing is measured. The laboratory environment temperature is $25^{\circ} \mathrm{C}$. From the temperature measured by infrared thermal imager, it can be found that the maximum surface temperature of the motor shell is $71.8^{\circ} \mathrm{C}$ and the finite element result is $69.6^{\circ} \mathrm{C}$. The deviation rate is just $3.2 \%$, which is within the allowable deviation range in engineering.

\section{Conclusions}

In this paper, using the finite element method, the influences of the 5th, 7th, 11th and 13th harmonic currents with different amplitudes on the air gap magnetic field, torque ripple, eddy current loss and temperature field of PMSM are analyzed, the following conclusions can be obtained:

1) When the 5th, 11th harmonic currents were input into the stator armature windings, the motor air gap fundamental wave magnetic field content decreases; when the 7th and 13th harmonic currents were input into the stator armature windings, the motor air gap fundamental wave magnetic field content increases. The air gap magnetic density maximum value caused by the 5th and 11th harmonics becomes small, and the average value increases. The air gap flux density maximum value caused by the 7th and 13th harmonics becomes large, and the average value decreases.

(2) The motor average torque is not affected by the harmonic currents with different amplitudes. However, with the increase of the harmonic current amplitude, the range of the motor torque fluctuation is bigger, the higher the torque ripple coefficient of the motor is, the worse the motor stability is. When the harmonic initial phase changes within $360 \mathrm{deg}$, the change of the torque ripple coefficient and the average torque ripple range caused by the lower order harmonic is larger than that caused by the higher order harmonic.

(3) With the same amplitude of the harmonic current, the higher the harmonic order is, the greater the eddy current loss is, and the higher the temperature rise of the permanent 
magnets is. In addition, with the increase of the harmonic amplitude, the eddy current loss of the rotor increases, and the permanent magnets temperature rise also increases. However, the increase of the loss caused by the higher order harmonics is significantly higher than that caused by the lower order harmonics. The variation regularity of the eddy current loss caused by each harmonic and the temperature rise of the permanent magnet is sinusoidal with the change of the harmonic initial phase. When the harmonic initial phase changes within $360 \mathrm{deg}$, the change of the eddy current loss and permanent magnet temperature rise caused by the lower order harmonic is larger than that caused by the lower order harmonic.

\section{Acknowledgments}

This work was supported in part by the National Natural Science Foundation of China under Grant 51507156, in part by the University Key Scientific Research Programs of Henan province under Grant 17A470005, in part by the Doctoral Program of Zhengzhou University of Light Industry under Grant 2014BSJJ042, and the part by the Graduate Scientific and Technology Innovation Foundation of Zhengzhou University of Light Industry under Grant 2016001.

\section{References}

[1] Liang W., Wang J., Luk C.K., Fang W., Fei W., Analytical Modeling of Current Harmonic Components in PMSM Drive With Voltage-Source Inverter by SVPWM Technique, IEEE Transactions on Energy Conversion, vol. 29, no. 3, pp. 673-680 (2014).

[2] Cao W., Bradley K.J., Clare J.C., Wheeler P.W., Comparison of Stray Load and Inverter-Induced Harmonic Losses in Induction Motors Using Calorimetric and Harmonic Injection Methods, IEEE Transactions on Industry Applications, vol. 46, no. 1, pp. 249-255 (2010).

[3] Yamazaki K., Suzuki A., Ohto M., Takakura T., Harmonic Loss and Torque Analysis of High-Speed Induction Motors, IEEE Transactions on Industry Applications, vol. 48, no. 3, pp. 933-941 (2012).

[4] Lee S., Kim Y.J., Jung S.Y., Numerical Investigation on Torque Harmonics Reduction of Interior PM Synchronous Motor with Concentrated Winding, IEEE Transactions on Magnetics, vol. 48, no. 2, pp. 927-930 (2012).

[5] Jeong T.C., Kim W.H., Kim M.J., Lee K.D., Lee J.J., Han J.H. et al., Current Harmonics Loss Analysis of 150-kW Traction Interior Permanent Magnet Synchronous Motor Through Co-Analysis of dlhbox $\{-\} q$ Axis Current Control and Finite Element Method, IEEE Transactions on Magnetics, vol. 49, no. 5, pp. 2343-2346 (2013).

[6] Yamazaki K., Abe A., Loss Investigation of Interior Permanent-Magnet Motors Considering Carrier Harmonics and Magnet Eddy Currents, IEEE Transactions on Industry Applications, vol. 45, no. 2, pp. 659-665 (2009).

[7] Wang J., Performance evaluation of fractional-slot tubular permanent magnet machines with low space harmonics, Archives of Electrical Engineering, vol. 64, no. 4, pp. 655-668 (2015).

[8] Dolecek R., Novak J., Cerny O., Nemec Z., Research of harmonic spectrum of currents in traction drive with PMSM, IEEE International Symposium on Industrial Electronics, Gdansk, pp. 710-715 (2011).

[9] Hwang J.C., Wei H.T., The Current Harmonics Elimination Control Strategy for Six-Leg ThreePhase Permanent Magnet Synchronous Motor Drives, IEEE Transactions on Power Electronics, vol. 29, no. 6, pp. 3032-3040 (2014).

[10] Nakai T., \& Fujimoto H., Harmonic Current Suppression Method of PMSM Based on Repetitive Perfect Tracking Control, Industrial Electronics Society, 33rd Annual Conference of the IEEE, Taipei, pp. 3032-3040 (2007). 
[11] Boglietti A., Cavagnino A., Ionel D.M., Popescu M., Staton D.A., Vaschetto S., A General Model to Predict the Iron Losses in PWM Inverter-Fed Induction Motors, IEEE Transactions on Industry Applications, vol. 46, no. 5, pp. 1882-1890 (2010).

[12] Wang T., Fang F., Wu X., Jiang X., Novel Filter for Stator Harmonic Currents Reduction in SixStep Converter Fed Multiphase Induction Motor Drives, IEEE Transactions on Power Electronics, vol. 28, no. 1, pp. 498-506 (2013).

[13] Chaithongsuk S., Takorabet N., Meibody-Tabar F., On the Use of Pulse Width Modulation Method for the Elimination of Flux Density Harmonics in the Air-Gap of Surface PM Motors, IEEE Transactions on Magnetics, vol. 45, no. 3, pp. 1736-1739 (2009).

[14] Wang Z., Chen J., Zhang B., Zheng Y., Phase-shifted chaotic SVM for harmonic performance improvement in paralleled voltage-source inverters fed PMSM drive, International Power Electronics and Application Conference and Exposition, Shanghai, pp. 670-675 (2014).

[15] Lu J., Yang J., Ma Y., Ren R., Compensation for harmonic flux and current of permanent magnet synchronous motor by harmonic voltage, International Symposium on Knowledge Acquisition and Modeling, Fukuoka, pp. 1-5 (2015).

[16] Lee G.H., Kim S.I., Hong J.P., Bahn J.H., Torque Ripple Reduction of Interior Permanent Magnet Synchronous Motor Using Harmonic Injected Current, IEEE Transactions on Magnetics, vol. 44, no. 6, pp. 1582-1585 (2008).

[17] Li W., Wang J., Zhang X., Kou B., Loss calculation and thermal simulation analysis of high-speed PM synchronous generators with rotor topology, International Conference on Computer Application and System Modeling, Taiyuan, 2010, pp. V14-612-V14-616 ( 2010).

[18] Witczak P., Kubiak W., Lefik M., Szulakowski J., Modal-frequency spectrum of magnetic flux density in air gap of permanent magnet motor, Archives of Electrical Engineering, vol. 63, no. 1, pp. 29-46 (2014).

[19] Zhou C., Yang G., Su J., PWM Strategy With Minimum Harmonic Distortion for Dual Three-Phase Permanent-Magnet Synchronous Motor Drives Operating in the Over modulation Region, IEEE Transactions on Power Electronics, vol. 31, no. 2, pp. 1367-1380 (2016).

[20] Li Y., Zhou J., Xia J., Meng H., Research on vibration and noise of permanent magnet motor under low order harmonic current, Transportation Electrification Asia-Pacific IEEE, Beijing, pp. 1-5 (2014).

[21] Li W., Yu Z., Chen Y., Calculation and Analysis of Heat Transfer Coefficients and Temperature Fields of Air-Cooled Large Hydro-Generator Rotor Excitation Windings, IEEE Transactions on Energy Conversion, vol. 26, no. 3, pp. 946-952 (2011). 